\title{
A Field Research on Organizational Learning, Crisis Management Capability and Firm Performance
}

\author{
Cemal Zehir ${ }^{\mathrm{a}}$, Mahmut Yavuz ${ }^{\mathrm{b}}$ \\ ${ }^{a} Y_{l} l d l z$ Technical University, Istanbul, 34220, Turkey \\ ${ }^{c}$ Gebze Institute of Technology, Kocaeli, 41400, Turkey
}

\begin{abstract}
Turkey has experienced a series of crises in 1994, 1999 and 2001, which induced remarkable damage in Turkish economy. Thus crisis management has been the main topic in Turkish agenda so many years. Besides crisis management, organizational learning also has been focused as an affective crisis management mean. Crisis preparedness process which is a part of crisis management is vital for any organization's existence because the emergence of crises is inevitable. Therefore the crisis preparedness has been a topic of increasing importance for organizations seeking an effective way to fight against potential crises. In this context, this research aim to investigate the relationship among the crisis preparedness capability, organizational learning capability and organizational performance. This survey is conducted on 400 managers of 114 firms operating in the Marmara region. SPSS 15.0 statistics package program was used to analyze the data obtained from 400 questionnaires. Factor analysis, and reliability analysis have been executed to reveal the reliability of scale, and correlation and regression analyses have been executed to reveal the relationship among the crisis preparedness capability, organizational learning capability, and organizational performance.
\end{abstract}

Key words: Organizational Learning, Crisis Management Capability, Firm Performance

JEL: B 25, D03, D23

(C) 2014 Published by SSBFNET

\section{Introduction}

Although major economic crises in Turkey in 1994, 1999, and 2001 created heavy blows to economy, at the same time firms learned a lot from these crises. Firms that managed these crises in a good way and also learned from these crises succeeded to exist and became more powerful but the others who were unable to do so vanished. Firms that used the experience gained from previous crises were not affected too much from the financial crisis which resulted from 2008-2009 American finance companies and surrounded the world. This study is initiated on the basis of the opinion that companies which managed to survive in spite of the crises are not incidentally alive. 
Crises do not only create losses but also create earnings. In the time of crisis firms' loss or gain depend on a lot of factors such as the triggering reasons of the crisis and the shape of the solutions. There is no single method for crisis management and researchers should focus on one or more elements of this process. Crisis management teams (Nelson-Horchler, 1986), crisis management plan (Truitt and Kelly, 1989), preparation for a crisis (Reilly, 1993; Carmeli and Schaubroeck, 2008), and crisis preparedness activities (Pauchant and Mitroff, 1992; Elsubbaugh et al., 2004) can be some examples.

Crisis management is a function that helps to minimize the potential damage to the firm by taking situation under control and also collection of activities includes taking advantage of opportunities from crisis (Mitroff, 1988). Pearson and Clair (1998) defined crisis management as a systematic process enabling businesses to continue normal activities and minimizing losses of stakeholders. The main objective of the implementation of crisis management in the organizations is to provide self esteem at all levels of the organization by protecting organization from the negative effects of the crisis and preventing the degradation and dissolution of the organizational climate. The other objectives of crisis management are pre sensing the crises, distinguishing their types, taking measures against them, and organizational restructuring by learning many things from crises in many areas as soon as possible (Pearson and Mitroff, 1993).

In this context, crisis preparedness process which is a part of crisis management is vital for any organization's existence because the emergence of crises is inevitable. Therefore the crisis preparedness has been a topic of increasing importance for organizations seeking an effective way to fight against potential crises. Recent research findings show that the majority of the dramatic crises arised in the last two decades could have been prevented or the effects could have been minimized if the employees and the managers had been prepared for crises (Elsubbaugh et al. 2004).

Crisis preparedness process, provide a competitive advantage if it is in accordance with the process of organizational learning. Organizational learning emerge as one of the main determinants to cope with the crises faced by the organization. Therefore if the organizational learning and crisis preparedness are paired correctly, crisis can become a potential source of healing rather than a risk that disrupts the balances.

Farrell, Ockowski and Kharabsheh (2008) who handled organizational learning in the context of resource-based view, claim that organizational learning allows firms superior performance compared to its competitors and it is succeeded if Barney(1991)'s all four criteria are meet (Özşahin, 2011:48). According to Farrell et al (2008), organizational learning is valuable because it allows businesses to assess opportunities by minimizing the threats around the business. Organizational learning is capable of being rare because it is one of the productive learning resources. A successful organizational learning can not be imitated due to the its complexity. Finally, organizational learning gives company a competitive advantage because it is not substitutable. In this direction, taking organizational learning as a capability is not wrong. 
Alegre and Chiva (2008) defines organizational learning capability as "open and confidential sources or capabilities used by enterprises to gain competitive advantage" by using learning, organizational learning and talent definitions in literature and they state that these capabilities make organizational learning process possible.

This study investigates the behaviors and capabilities that sustain businesses in the times of crisis and also intends to reveal the crisis preparedness capability's relation with organizational learning capability and organizational performance. In this context, after defining crisis preparedness capability, organizational learning capability and organizational performance concepts briefly, in the metedology section the relationships between them will be discussed in detail empirically. Research findings and recommendations for further studies will be included in the conclusion section of the study.

\section{Theoretical Framework}

\subsection{Crisis Preparedness Capability}

Perrow states that organizational systems are complex and have deficiencies therefore they are open to crises (Perrow, 1984). All organizational systems are deficient and the increase in business complexity increases susceptibility to crisis. Therefore, systems should be designed in way to manage crisis effectively by learning from failures. Crisis management means evaluating a company's main products, services, production processes, workers, and different events and forces that pose a threat, by connecting with each other in an ongoing process (Carmeli and Schaubroeck, 2008). According to Mitroff (1988), this process includes key plans for crisis preparation, design and implementation of procedures and mechanisms, putting crisis under pressure by defining it, and finally fully recovering organization and learning from this experience.

At some points, the inevitability of the emergence of crises shows that crisis preparedness is vital for any organization's existence. Therefore, crisis preparedness has been a topic of increasing importance for organizations that seek an effective way to cope with crises.

According to Kovoor-Misra et al, a clear understanding of the characteristics of a crisis has a critical importance for estimating, directing and controlling crisis. For example, if a crisis suddenly erupts, being prepared in advance and sustaining response capabilities to crises will have a critical importance. When a crisis occurs, there is a limited time to activate sources. On the contrary, if a crisis is predicted, top managers can warn others in advance and sources to respond can be activated. (Kovoor-Misra et al., 2001).

Crisis preparedness process is the stage of taking necessary measures and determing ways to avoid crisis by anticipating potential crisis situations in advance (Bayazit et al, 2003). Crisis preparedness capability refers to the level of the readiness of the organization to deal with the ongoing or coming crisis situations (Carmeli and Schaubroeck, 2008). Pearson and Clair state the crisis perception of the managers as the most important determinant of the crisis preparedness capabilities. If the managers are sensitive to the risk of future crises and give necessary importance to the signals, organizations will tend to practice crisis management program (Pearson and Clair, 1998). 
Carmeli and Schaubroeck (2008) point out that crisis preparedness capabilities differ according to organization's structure, culture and policies because crisis management is a complex and generic process including activities related to all these factors. Parallel to Carmeli and Schaubroeck, Mitroff (1988) sees culture as one of the determinants of crisis preparedness capability. According to Mitroff, organizational culture is one of the most important determinants used to understand how the organization respond to crises and how to cope with "early warning signals".

Elsubbaugh et al (2004) in their crisis management evaluation studies, emphasized the importance of "cultural preparation", "strategic preparation" and "detection of early warning signals" as the most important elements of crisis preparedness capabilities. The first step of the crisis preparedness process which is also called as general preparation process covers developing a healthy organizational culture (including values and beliefs) that cares crisis management by adapting crisis management as a part of strategic planning process. The second step of the crisis preparedness capability is the detection of early warning signals phase in which organizations' crises signals are identified and interpreted. (Elsubbaugh et al, 2004:124-125).

In this study, in accordance with the Crisis Readiness Model (2004: 124) predicted by Elsubbaugh and colleagues, "creating crisis management culture", "strategic activities towards the crisis", and "creating early warning system" will be discussed as the dimensions of crisis preparedness capability and their relations with the organizational learning capability and organizational performance will be investigated. The dimensions are defined briefly as follows.

Creating A Crisis Management Culture: The first step of the effective crisis preparation phase, general preparation process, starts with creating values and beliefs culture that gives importance to crisis management. (Elsubbaugh et al, 2004). Although Reilly (1987) remarks that a healthy crisis management culture has a vital importance for developed countries, healthy crisis management is not vital only for developed countries but also equally vital for developing countries that are exposed to crises continuously like Turkey. Elsubbaugh et al. (2004) emphasize that a wellstructured crisis management culture facilitates strategic planning towards crisis and supports crisis management activities. Similarly Pearson and Clair (1998), and Mitroff et al. (1989) said that culture that prepares organizations for crises in the best way is one of the most important elements of the crisis preparation. Without an organizational culture that covers all hierarchical levels of the organization and supports current and potential crisis management, it is not seen possible for businesses to manage crisis in an effective way (Elsubbaugh et al., 2004).

Strategic Activities Towards The Crisis: The second important pillar of crisis preparation is integrating crisis management with strategic management (Perrow, 1984; Fink, 1986; Pearson et al., 1997). Pauchant and Mitroff (1992) noted that businesses should include crisis in their strategic plans and evaluate their decisions related to how they will act in the event of future crises. In other words, today's businesses should develop plans in which crisis management is integrated into strategic plans and crisis management should become one part of the strategic planning (Pauchant and Mitroff, 1992). Elsubbaugh et al. (2004) show examples of integrating crisis management into strategic management such as making crisis management as one of the elements of the total quality management, creating crisis management teams and making top management as one part of these teams. Other strategic activities in the 
context of addressing current crises and preparing for potential crises are listed as ensuring customer satisfaction, equipment and product quality improvement, quality control system improvement and giving importance to training activities for crisis (Elsubbaugh et al., 2004:117-119).

Creating Early Warning System: After creating a healthy culture for crisis management within the organization and completion of strategic activities, the final stage of preparation process, creating an early warning system, is reached. In this stage, the crisis signals are detected and interpreted by organizations. If these signals are not detected, seen or if they are misinterpreted, crisis management activities cannot be applied effectively. When the early warning signals are detected, organizations can prepare themselves for the anticipated crises (Elsubbaugh et al., 2004). Mitroff et al (1987) express the development of the early warning systems depending on the systematic and rational environmental scanning system as one of the managerial activities which will make organizations more secure. The signals detected by an organization's early warning system should be evaluated carefully by the top management and crisis prevention mechanisms should be activated. Otherwise, it is likely to commence a process that can go up to the liquidation of the organization (Weitzel and Jonsson, 1989). Although Elsubbaugh et al. (2004) indicate in their study that early warning systems of organizations have a very important place in crisis management, in practice it has been revealed that they do not give much importance. According to Tutar (2007), early warning system is an analytical technique used to predict an organization's success in advance and with the use of this technique, the situation of the business and the potential risks are quantitatively determined. Public opinion surveys, audits, agenda management committees, hotlines and environmental analysis (Smart and Vertinsky, 1977; Fink, 1986; Mitroff, 1988; Kovoor-Misra et al., 2001; Elsubbaugh et al., 2004) are included in the literature as the main early warning systems.

\subsection{Organizational Learning Capability}

Learning is defined as permanent changes in behaviors as a result of repetition and experiences (Teece, Pisano and Shui, 1997). Organizational learning is defined as a process in which organizations learn (Alegre and Chiva, 2008). In other words, organizational learning is a progress process of a competing organization in which environment and culture are specific, some tools and methods are used and managerial systems and know how are used to achieve integration in creation and improvement (Argyris and Schön 1978, 1996).

Farrell, Ockowski and Kharabsheh (2008) who handled organizational learning in the context of resource-based view, claim that organizational learning allows firms superior performance compared to its competitors and it is succeeded if Barney(1991)'s all four criteria are meet (Özşahin, 2011:48). According to Farrell et al (2008), organizational learning is valuable because it allows businesses to assess opportunities by minimizing the threats around the business. Organizational learning is capable of being rare because it is one of the productive learning resources. A successful organizational learning can not be imitated due to its complexity. Finally, organizational learning gives company a competitive advantage because it is not substitutable. In this direction, taking organizational learning as a capability is not wrong. 
Alegre and Chiva (2008) defines organizational learning capability as "open and confidential sources or capabilities used by enterprises to gain competitive advantage" by using learning, organizational learning and talent definitions in literature and they state that these capabilities makes organizational learning process possible.

Chen (2005) considers organizational learning as a process and organizational learning capability as a system. Chen (2005) sorts the dimensions of the organizational learning capability as "exploration, innovation, selection, application, transfer, reflection, knowledge acquisition, information provision, organizational memory creation”. In this study, depending on Chen's definition of the organizational learning capability, "process of obtaining and editing new knowledge to be able to adapt internal and external changes in the environment and to maintain and develop its sustainable existence", organizational learning capability is considered as a structure consisting of " discovering opportunities, exchange and knowledge in the environment, producing new ideas based on the discovered opportunities, exchange and knowledge, choosing the most suitable one from these ideas and knowledges, implementing the selected idea, experiencing, learning from past experiences, giving feedbacks, transferring this knowledge to others, obtaining information from the environment, providing information to the environment, and creating organizational memory".

\subsection{Organizational Performance}

Although almost all theoretical and empirical studies in the field of management literature are associated with firm performance, it is not possible to mention about a generally accepted and agreed firm performance definition (Bakoğlu, 2000; Harris and Ogbonna, 2001). Wheelen and Hunger defined organizational performance as "an activity related to an organizational unit needed to be measured or evaluation of targets to be realized". Hart and Banbury (1994) defined organizational performance as "a multidimensional structure including financial performance, operational performance and organizational performance dimensions". As defining the concept of organizational performance, the subjects of how to measure and what kind of scale to be used are also handled in different ways.

Venkatraman and Ramanujam (1986) offer a two-dimensional measuring classification for organizational performance. On the one hand scales are allocated according to the source of information as primary and secondary sources scales; on the other hand scales are categorized as financial (quantitative) and operational (qualitative) determinants. According to Venkatraman and Ramanujam's (1986) classification, in the primary source scale data are collected by the researcher himself from the company with the help of observation, experiment, survey and interview techniques; in the secondary source scale data are collected by evaluating, analyzing, summarizing and interpreting of the data collected before for other purposes (Independence, 2010; Gonzalez- Benito and Gonzalez- Benito, 2005). On the other hand, financial (quantitative) scales are related to the performance of accounting and economics such as profit and sales; and operational (qualitative) scales are related to operational success factors which can lead to financial performance such as customer satisfaction, quality, employee loyalty, market share, and new product development (Venkatraman and Ramanujam, 1986; Gonzalez- Benito and Gonzalez- Benito, 2005; Verbeet and Boons, 2009). 
Another classification for organizational performance includes objective measurement and subjective measurement which are related to whether data based on beliefs and opinions of the researcher. Objective measurements are related to financial indicators that are directly obtained from the company or secondary sources; and subjective measurements depend on the opinions and beliefs of the employees, managers or customers related to financial or operational indicators (Gonzalez-Benito and Gonzalez-Benito, 2005).

Qualitative or quantitative, objective or subjective, and primary or secondary measurements are conducted depending on the size and nature of the research. For example, in the studies on organizational behavior "qualitative" measurements such as job satisfaction, perceptions of fairness, employee or customer loyalty and satisfaction are used but in the studies conducted in the field of strategic management "quantitative" measurements such as return on assets, return on turnover, and return on investments are used. Again, in the studies of managerial behavior and organizational culture "subjective" measurements based on opinions and convictions are used to measure performance but in the studies of production management, accounting, finance and logistics "objective" measurements based on records, reports, and numbers are used (Özşahin, 2011). It is suggested that in the studies related to managerial ability and behavior it would be more appropriate to use subjective measurements which are also used by customers, employees, or managers to compare companies according to competitors or industry averages in the context of sales, profitability, market share, customer satisfaction level, new product performance rather than net figures (numeric values) (Khandwall , 1977; Jaworski and Kohli , 1993; Desphande et al. , 1993) ( Garg et al. , 2003). Regarding this context, in this study in which the effects of organizational learning capability and crisis preparedness capability on organizational performance are investigated, it is decided to use "subjective quantitative performance scale" which is also used by managers to measure organizational performance depending on their personal convictions using company sales, profitability, and image rather than net figures (Desphande et al. , 1993; Jaworski and Kohli , 1993; Khandwall , 1977).

\subsection{The Mediating Effect of Crisis Preparedness Capability on Organizational Learning Capability and Organizational Performance}

Organizations can improve their performance by using strategic values and capabilities (Wernerfelt, 1984).Strategic resources are valuable, rare and difficult to be imitated (Barney, 1991). As mentioned above, organizational learning capability is a factor that contributes positively to the performance of the business. However, in times of crisis businesses need more than organizational learning capability to maintain their existence and to enhance their performance. Indeed, it is known that some businesses are more effective than others in combating the crisis. The reason for this is that these businesses are prepared for such crises as the crisis could break out at any moment. According to Weick and Sutcliffe (2001), organizations ready to crisis exhibits a different mindset than the organizations open to crisis. Organizations ready to crisis continuously analyze operational and managerial structures and monitors potential hazards proactively. Crisis preparedness ability, the level of an organization's readiness to deal with current and future crisis situations (Carmeli and Schaubroeck, 2008), can provide a competitive advantage if it is appropriately associated with organizational learning ability (Roux-Dufort and Matais, 1999). 
With the organizational learning, a progress of an organization that constantly acquires new knowledge, adapts to internal and external changes in the environment and adapts to maintain and develop its sustainable existence Chen (2005), the environment is analyzed and it allows businesses to regulate strategic activities for crisis by creating early warning systems and also allows creating a crisis management culture by constantly doing this. Thus, when crisis occurs businesses, make crisis preparation with organizational learning, become more successful and realize higher performance than others that are not prepared. In this context, the following hypothesis is proposed in this study:

H1: In times of crisis, organizational learning ability improves organizational performance through crisis management ability.

\section{Methodology and Application}

\subsection{Research Sample and Data Collection}

In this research, survey method is used and data collected from medium and large sized 114 companies in the Marmara region in the years between 2010-2012. The questionnaire is prepared for managers working at various levels. Target population is selected from lower, middle and upper level managers because they have more information about organizational culture, vision, policy and performance than other workers. 2 to 5 managers from each firm are requested to fill out our survey.

Contact information of the medium and large sized companies in the Marmara region is provided by KOSGEB and 200 companies are selected randomly. Each company is contacted individually, informed about our work and asked whether they want to participate our survey or not. Face to face interviews are requested from companies which are easily accessible in terms of physical location. The reason for such a request is the high rate of return. 37 companies told that they cannot participate due to their company policies and 13 companies told that they would not participate without giving reasons. Some companies wanted to see the survey and it was sent to these companies to be reviewed by top and middle level managers. 9 more companies reported that they cannot answer the questions in the survey but 16 company executives filled out our questionnaire and sent back us via e-mail. Some companies did not make any return in 2 weeks although they saw the questionnaire, they were sent a second reminder e-mail again. After this reminder e-mail, 4 more companies filled out our survey. Despite the reminder e-mail, the responses of companies that did not return within three weeks are assumed to be negative. In total 116 companies participated our survey, 96 companies through face to face interviews and 20 companies via e-mail. 411 managers from 116 companies contributed to the study by filling out our questionnaire. 11 questionnaires were eliminated because they did not provide the required criteria and then remaining 400 questionnaires were subjected to analysis for evaluation. Surveys are taken from 3-4 managers on average from each company (number of questionnaires per company 3.5). 


\subsection{Scales Used In This Survey}

Organizational Learning Capability: The scale to measure organizational learning capability is adapted from Chen's article, "Management Practices and Tools for Enhancing Organizational Learning Capability". Chen (2005) proposes "Nine Organizational Learning Sub-Systems" by integrating theoretical and practical work in literature related to organizational learning and these sub-systems are listed as "discovering, innovating, selecting, executing, transferring, reflecting, acquiring knowledge from environment, contributing knowledge to environment, and building organizational memory". 9 questions was created based on the sentences used to describe these nine abilities and this 9-item scale was used to measure the learning ability of companies. For example, "Our ability to discover the emerging changes, problems, challenges and opportunities in the internal and external environment compared to our competitors" was used to measure discovering ability and participants were requested to evaluate according to 5 points Likert scale 1) Very bad-5) Very good. This formed scale was used for the first time in this study.

Crisis Management Capability: To measure crisis management capability 24-question questionnaire was adapted from the published study of Elsubbaugh, Fildes and Rose (2004), "Preparation for Crisis Management: A Proposed Model and Empirical Evidence". 11 questions are related to creating a culture of crisis management, 5 questions are related to the establishment of early warning systems for crisis and the remaining 8 questions are used to measure strategic activities related to crisis management. Participants are requested to evaluate the crisis preparedness of their companies according to 5 points Likert scale, (1) Very few-(5) Very high and this scale was used for the first time in such a study in Turkey.

Organizational Performance: Although in literature, both organizational performance-related quantitative and qualitative scales are used, in studies generally quantitative performance scales are preferred. It is possible to mention about widely used two types of quantitative performance scales: "objective quantitative performance scale”, based on numerical values such as net sales, return on investment ratio, activities or investment rate of return, and annual growth rate (Zahra and Bogner, 2000; Baum and Wally, 2003) and "subjective quantitative performance scale”, (for example; scales needed to measure a company's sales and profitability according to its competitors or the industry) based on the company evaluation of employees or managers on areas such as sales, and profitability image by using their personal convictions rather than numerical values (Desphande et al., 1993; Jaworski ve Kohli, 1993; Khandwalla, 1977). In this study, 12-item subjective performance scale is used by adapting from the literature mostly to measure the organization's financial strength and growth performance. This scale is prepared in 5 points Likert format (1.Very low-5.Very high) and participants are requested to evaluate their companies by considering sector averages according to financial criteria such as return on equity, net profitability, overall success level in financial terms and as well as growth criteria such as increase in the number of workers, sales growth, market share growth, and increase in the number of new customers. 


\section{Analysis and the Results}

\subsection{Data Analysis}

After factor, reliability and validity analyses are made by using 400 questionnaires, data is reduced to the firm level because the research is need to be operated at firm level. In order to reduce data to firm level, each firm was represented by a single survey data by taking averages of the data obtained from multiple participants from each company. Correlation and regression analyses were conducted with these 114 surveys which were reduced to the firm level. In order to evaluate the data SPSS (Statistical Package for the Social Sciences) 15.00 was used. Factor analysis was applied to questions in which Likert-type ordinal scale is used. The reliability of the factors was measured with Cronbach Alfa. One to one relationships among the variables were tested by correlation analysis, and regression analysis was used to test the research hypotheses.

\subsection{Factor Analysis and Reliability Analysis}

In our study, 45 questions were prepared according to 5 points Likert scale to measure variables and these questions were tested with the exploratory factor analysis using SPSS 15.00. As a result of factor analysis, all questions were loaded to their own factors and 45 questions were distributed to 3 factors. Cronbach Alfa values belong to these three factors are found generally greater than 0.90 and this shows that the scales used in this study have high reliability. Factor loadings and Cronbach Alfa values of the factor and reliability analysis of the organizational learning capability, learning from crisis experiences, and organizational performance are given in Table 1.

Table 1: Factor Analysis Results for Variables

\begin{tabular}{l}
\hline QUESTIONS \\
\begin{tabular}{l}
\hline Applying financial reforms \\
Giving importance to crisis management in training and work programs
\end{tabular} \\
Integrating crisis management into strategic planning \\
Ensuring an effective internal and external communication and giving \\
importance to public relations
\end{tabular}


Information Technologies are used

Giving importance to crisis management among employees $\quad, 661$

Importance of crisis management is known by everybody ,658

Following up new changes $\quad, 645$

Understanding the need to make fast decisions and taking action $\quad, 636$

Establishing specific teams to investigate internal and external problems $\quad, 626$

Improving equipment, product quality, operations and adopting quality $\quad$,624

control system

Giving attention to research and development activity $\quad$,622

Auditing important functional indicators such as financial indicators $\quad, 581$

Participation of top management to crisis management activities $\quad$,566

Emphasizing customer's satisfaction $\quad$,521

Our ability to create new ideas in order to cope with discovered changes, problems, challenges and opportunities

Our ability to make appropriate choices among alternatives in order to cope

with discovered changes, problems, challenges and opportunities

Our ability to discover emerging changes, problems, challenges and

opportunities in the internal and external environment

Our ability to benefit from the information taken as feedback from finished

and past experiences

Our ability to put new ideas and information into practice in order to cope

with discovered changes, problems, challenges and opportunities

Our ability to contribute to meaningful information we have achieved

Our ability to obtain the needed information from external environment

field into other areas within the business

Our ability to store information achieved, identified, and developed from

knowledge and experiences by grading

Net profitability before tax compared to all available resources

Net revenue achieved from basic operations

Average net profitability compared to equity $\quad, 810$

Overall level of profitability , ,786

Average annual increase in sales, 741

Increase in the number of new products offered to market, 740

Overall success level in financial terms, 732

In general, position in the competitive market environment ,705

Financial success of the new products offered to market., 693

Increase in market share compared to the leading competitors $\quad, 665$

Increase in the number of new customers, 657

Increase in the number of employees 


\subsection{Correlation Analysis}

Correlation analyses were carried out in two stages. In the first stage, as shown in Table 2, one to one relationships among organizational learning capability, crisis preparedness capability, and organizational performance were analyzed and it was found that these three have a significant relationship with each other at $\mathrm{p}<0.01$ level. Then, data obtained from 400 managers were reduced to firm level and correlation analysis was repeated on the 114 observed data. Reduction process was conducted by taking averages of each data, which were obtained from multiple participants in each company, within themselves. Repeated analysis results on reducted variables revealed significant correlations among variables at $\mathrm{p}<0.01$. Table 2 includes averages of the variables, standard deviations and correlation coefficients. Correlation coefficients of the measurement variables (400 observed data) are given in the upper diagonal of the matrix in Table 2 and correlation coefficients of reducted variables (114 observed data) are given in the lower diagonal of the matrix.

Table 2. Mean, Standard Deviation Values and Correlation Coefficients of Variables

\begin{tabular}{|c|c|c|c|c|c|}
\hline VARIABLES & 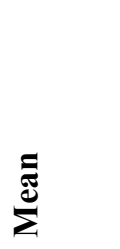 & 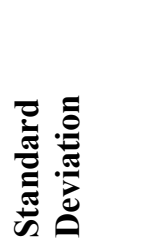 & U & 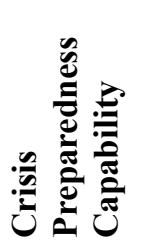 & 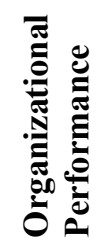 \\
\hline Organizational Learning Capability & 3,92 & 0,55 & 1 & ,773** & ,612** \\
\hline Crisis Preparedness Capability & 3,84 & 0,68 &, $815 * *$ & 1 &, $687 * *$ \\
\hline Organizational Performance & 3,75 & 0,62 &, $639 * *$ &, $686 * *$ & 1 \\
\hline
\end{tabular}

Correlation coefficients at the bottom of the diagonal was obtained from the factors reduced to firm level; the upper side was obtained from measurement variables. Pearson Correlation is significant at $* *: p<0.01$ level.

\subsection{Projected General Regression Model and Hypotheses}

In this study, the mediating effect of the crisis preparedness capability on organizational learning capability and organizational performance is investigated and $\mathrm{H} 1$ hypothesis (In times of crisis, organizational learning ability improves organizational performance through crisis management ability) is created for the estimated overall research model and tested with regression analyses. In the regression analyses to support our hypothesis the following criteria are required: crisis preparedness capability should have significant relationships with organizational learning capabilities and organizational performance; crisis preparedness capability should have significant relationship with organizational performance; when organizational learning capability and crisis preparedness capability are included together in to the regression analysis as independent variables it is required that the significant effect of organizational learning on organizational performance should disappear. 
Table 3. Regression Analysis of The Mediating Effect of Crisis Preparedness Capability Between Organizational Learning Capability and Organizational Performance

\begin{tabular}{|c|c|c|c|c|c|c|}
\hline & $\begin{array}{l}\text { Independent } \\
\text { Variables }\end{array}$ & $\begin{array}{l}\text { Dependent } \\
\text { Variables }\end{array}$ & $\begin{array}{l}\text { Standardized } \\
\beta\end{array}$ & Sig. & $\begin{array}{l}\text { Adjusted } \\
\mathbf{R}^{2}\end{array}$ & F Value \\
\hline $\begin{array}{l}\text { 1st } \\
\text { Regression }\end{array}$ & $\begin{array}{l}\text { Organizational } \\
\text { Learning Capability }\end{array}$ & $\begin{array}{l}\text { Organizational } \\
\text { Performance }\end{array}$ &, $639 * * *$ & ,000 & 403 & 77,288 \\
\hline $\begin{array}{l}\text { 2nd } \\
\text { Regression }\end{array}$ & $\begin{array}{l}\text { Organizational } \\
\text { Learning Capability }\end{array}$ & $\begin{array}{l}\text { Crisis } \\
\text { Management } \\
\text { Ability }\end{array}$ &, $815^{* * *}$ & ,000 & 661 & 221,808 \\
\hline $\begin{array}{l}\text { 3rd } \\
\text { Regression }\end{array}$ & $\begin{array}{l}\text { Organizational } \\
\text { Learning Capability }\end{array}$ & $\begin{array}{l}\text { Organizational } \\
\text { Performance }\end{array}$ &, $686^{* * *}$ & ,000 & 465 & 99,401 \\
\hline \multirow{2}{*}{$\begin{array}{l}\text { 4th } \\
\text { Regression }\end{array}$} & $\begin{array}{l}\text { Organizational } \\
\text { Learning Capability }\end{array}$ & \multirow{2}{*}{$\begin{array}{l}\text { Organizational } \\
\text { Performance }\end{array}$} &, 239 & ,044 & \multirow[t]{2}{*}{,480 } & \multirow[t]{2}{*}{53,172} \\
\hline & $\begin{array}{l}\text { Crisis Preparedness } \\
\text { Capability }\end{array}$ & &, $491 * * *$ & ,000 & & \\
\hline
\end{tabular}

$* * *: \mathrm{p} \leq 0.001$

As it is seen in Table 3, organizational learning ability significantly affects crisis preparedness, ability $(\mathrm{p}=0.000, \beta=$ $815, \mathrm{R} 2=, 661)$ and organizational performance $(\mathrm{p}=0.000, \beta=639, \mathrm{R} 2=, 403)$. Regression analysis shows that crisis preparedness capability also significantly increases organizational performance $(p=0.000, \beta=686, \mathrm{R} 2=, 465)$. In the 4th regression, when learning capability and crisis preparedness capability are considered together as independent variables, the significant relationship between crisis preparedness capability and organizational performance at $p$ $<0.001$ level is maintained $(\mathrm{p}=0.000 ; \beta=, 491)$, but the significant relationship between organizational performance and organizational learning capability at $\mathrm{p}<0.001$ level disappeared $(\mathrm{p}=0.044 ; \beta=, 239)$. This shows us that crisis preparedness capability has a mediating effect between organizational learning capability and organizational performance and also shows that our hypothesis H1 (In times of crisis, organizational learning ability improves organizational performance through crisis management ability) is supported.

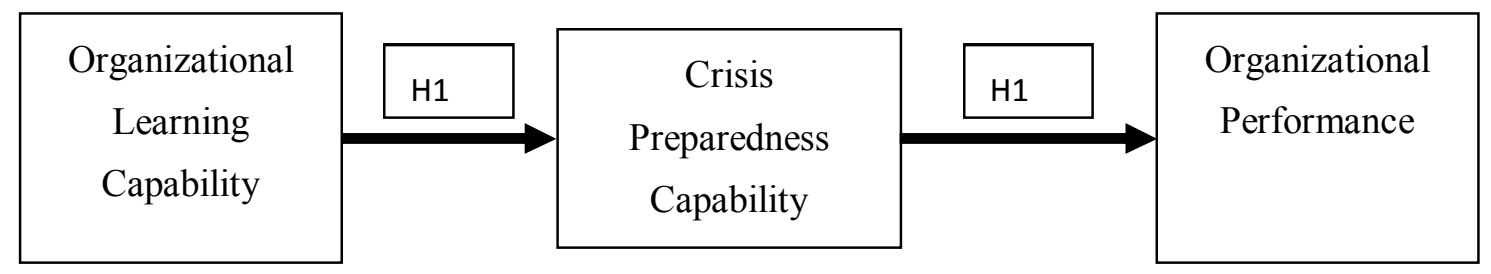

Figure 1. Regression Model of The Mediating Effect of Crisis Preparedness Capability Between Organizational Learning Capability and Organizational Performance

\section{Conclusion}

The ability of organizations to cope with crisis become indispensable for countries constantly exposed to the crisis like Turkey. Businesses that are successful in managing the crisis maintain their existence and also turn crises into 
opportunities but on the other hand businesses that are not successful in managing the crisis tend to disappear. When we investigate the characteristics of these businesses that are succeeded to survive, even managed to perform high performance in times of crisis in Turkey, organizational learning capability and crisis preparedness capability emerge as the two most important elements.

In this study, the data were obtained from 114 companies' 400 or so lower, middle and upper managers that operate in the Marmara region and analyzed with SPSS 15 statistical package program. Organizational performance has been associated with organizational learning capability and crisis preparedness capability in times of crisis. In order to see the relationships among these three factors, correlation analysis was carried out and these three factors were found to be associated with one another at a high rate $(\mathrm{p} \leq 0.001)$. In the regression analysis that was made to test hypothesis and the direction of the relationships, it is found that organizational learning capability significantly affected crisis preparedness capability $\left(p=0.000 ; \beta=, 815 ; R^{2}=, 661\right)$ and organizational performance $\left(p=0.000 ; \beta=, 639 ; R^{2}=, 403\right)$ and in a similar way crisis preparedness capability significantly increased organizational performance $(p=0.000 ; \beta=, 686$; $\mathrm{R}^{2}=$,465). In the last regression analysis in which learning capability and crisis preparedness capability are considered together as independent variables and organizational performance as dependent variables, the significant relationship between crisis preparedness capability and organizational performance at $p<0.001$ level is maintained $(p=0.000$; $\beta=, 491$ ), but the significant relationship between organizational performance and organizational learning capability at $\mathrm{p}<0.001$ level disappeared $(\mathrm{p}=0.044 ; \beta=, 239$ ). With the inclusion of crisis preparedness capability into regression analysis, the significant relationship between organizational learning capability and organizational performance was disappeared and this shows that H1 (In times of crisis, organizational learning ability improves organizational performance through crisis management ability) hypothesis is supported. Thus, the result related to the mediating effect of the crisis of preparedness capability between organizational learning capability and organizational performance was achieved for the first time in this study.

In the light of the research findings, some recommendations can be made to managers who want to improve their performance by coping with crises successfully in times of the crisis. Supporting organizational learning capability with crisis preparedness capability, improving organizational learning capability by constantly analyzing and adapting to the environment, creating a culture for crisis management, engaging in strategic activities and setting up early warning systems are some of the recommendations to these managers.

This research was conducted on SME (Small and Medium sized Enterprises) managers operating in Turkey. To improve the generalizability of the findings, the same study can be implemented on large-scale enterprises in Turkey and businesses in different countries have different cultures. Also, other factors (eg, organizational culture, organizational structure, etc.) that improve organizational performance by improving crisis preparedness capability in times of crisis can be investigated. 


\section{References}

Alegre, J. and Chiva, R. (2008). Assessing the Impact of Organizational Learning Capability on Product Innovation Performance: An Empirical Test. Technovation, 28, pp.315-326.

Argyris, C., Schön, D. (1978). Organizational Learning: A Theory of Action Perspective, Reading, MA: Addison Wesley (Spector, J.M. ve Davidsen, P.I., How Can Organizational Learning be Modeled and Measured?. Evaluation and Program Planning, 2006, 29:63-69).

Argyris, C., Schön, D. (1996). Organizational Learning II: Theory, Method and Practice, Reading, MA: Addison Wesley (Guoquan Chen, Management Practices and Tools for Enhancing Organizational Learning Capability. SAM Advanced Management Journal, 2005, Winter, ss.4-35).

Bakoğlu, Refika (2000). Örgütsel Performans Kavramı ve Gelişimi. Öneri Dergisi, (15), ss. 39-45.

Barney, J.B. (1991). Firm Resources and Sustained Competitive Advantage. Journal of Management, 17 (1) pp.99120.

Baum, R.J. and Wally, S (2003). Strategic Decision Speed and Firm Performance. Strategic Management Journal, 24, pp.1107-1129.

Bayazıt, Z.D., Ö. Çengel ve F.F. Tepe. (2003). İşletmelerde Kriz Yönetimi ve Bir Vaka Çalışması. 11. Ulusal Yönetim ve Organizasyon Kongresi Bildiriler Kitabı, Afyon.

Carmeli, A. ve Schaubroeck, J. (2008). Organizational crisis-preparedness: The importance of learning from failures. Long Range Planning 41, 177-196.

Chen, Guoquan (2005). Management Practices and Tools for Enhancing Organizational Learning Capability. SAM Advanced Management Journal, Winter, ss.4-35.

Desphande, R., Farley, J.U. and Webster, F. (1993). Corporate Culture, Customer Orientation, and Innovativeness in Japanese Firms: A Quadrad Analysis. Journal of Marketing, Vol. 57, January, pp.23-37.

Elsubbaugh, S.; Fildes, R.ve Rose, M.B. (2004). Preparation for Crisis Management: A Proposed Model and Empirical Evidence. Journal of Contingencies and Crisis Management, Vol.12, No.3, 112-127.

Farrell, M. A., Oczkowski, E. and Kharabsheh, R. (2008). Market Orientation, Learning Orientation and Organizational Performance in International Joint Ventures. Asia Pacific Journal of Marketing Logistics, Vol. 20, No.3, pp.289-308.

Fink, S. (1986). Crisis management: Planning for the inevitable. AMACOM, New York

Garg, V.K., Walters, B.A. and Priem, R.L. (2003). Chief Executive Scanning Emphases, Environmental Dynamism and Manufacturing Firm Performance. Strategic Management Journal, (24), 725-744.

Gonzalez-Benito, Oscar and Gonzalez-Benito, Javier (2005). Cultural vs. Operational Market Orientation and Objective vs. Subjective Performance: Perspective of Production and Operations. Industrial Marketing Management, 34, pp.797-829.

Hargadon, A. (2000). Building an Innovation Factory. Harvard Business Review, 78 (3): 157-166.

Harris, L. and Ogbonna, E. (2001). Strategic Human Resource Management, Market Orientation, and Organizational Performance. Journal of Business Research, 51 (2), pp.157-166.

Hart, S. and Banbury, C. (1994). How Strategy Making Process Can Make a Difference. Strategic Management Journal, 15 (4), pp. 251-269.

Jaworski, Bernard J. ve Kohli, Ajay K. (1993). Market Orientation: Antecedents and Consequences. Journal of Marketing, 57 (July), pp.53-70. 
Khandwalla, Pradiph N. (1977). The Design of Organizations. Harcourt, Brace Javanovich Inc. USA.

Kovoor-Misra, S., Clair, J.A. and Bettenhausen, K.L. (2001). Clarifying the attributes of organizational crises. Technological Forecasting and Social Change 67(1), pp:77-91.

Kovoor-Misra, S., Clair, J.A. and Bettenhausen, K.L. (2001). Clarifying the attributes of organizational crises. Technological Forecasting and Social Change 67(1), pp:77-91.

Kurtuluş, Kemal (2010). Araştırma Yöntemleri. Türkmen Kitabevi, İstanbul.

Mitroff, I. et al. (1989). Do some organizations cause their own crises? The cultural profiles of crisis prone vs. crisisprepared organizations. Industrial Crisis Quarterly, Vol.3, pp.269-283.

Mitroff, I., Shrivastava, P. ve Udwadia, F. (1987). Effective Crisis Management. The Academy of Management Executive, Vol.1, No.3, ss.283-292.

Mitroff, I.I. (1988). Crisis Management: Cutting through the confusion. Sloan Management Review 29(2) 15-20.

Nelson-Horchlerr, J. (1986). Advent of crisis teams:will all companies have "command centers"?. Industry Week, 13 October,20.

Özşahin, M. (2011). Yüksek Performanslı Işsletmelerde Liderlik, Rekabeçi Kültür ve Performans İlişkisi. Gebze Yüksek Teknoloji Enstitüsü Sosyal Bilimler Enstitüsü, Doktora Tezi, İşletme Anabilim Dalı, Gebze.

Pauchant, T., ve Mitroff, I.I. (1992). Transforming Criss-prone Organization: Preventing individual, organizational and environmental tragedies. San Francisco: Jossey-Bass.

Pearson, C. , Clair, J., Kovoor-Misra, S. ve Mitroff, I. (1997). Managing the unthinkable. Organizational Dynamics, Vol.2, No.26, pp.51-64.

Pearson, C. M. ve Mitroff, I.I. (1993). From Crisis Prone to Crisis Prepared: A Framework for Crisis Management. Academy of Management Executive, 7, 48-59.

Pearson, C. M. ve Clair, J. (1998). Reframing Crisis Management. Academy of Management Review 23, 59-76.

Perrow, C. (1984). Normal Accidents: Living with High-risk Technologies. Basic Books, New York

Reilly, A.H. (1987). Are organizations ready for Crisis? A Managerial Scoreboard. Colombia Journal of World Business, Volume 22, Number 1, pp.79-88.

Reilly, A.H. (1993). Preparing for the worst: the process of effective crisis management. Industrial and Environmental Crisis Quarterly,7,2, 115-144.

Roux-Dufort, C. ve Matais, E. (1999). Building Core Competencies in Crisis Management Through Organizational Learning. Technological Forecasting and Social Change, 113-127

Smart, C and Vertinsky, I. (1984). Strategy and the Environment: A Study of Corporate Response to Crises. Strategic Management Journal 5, pp. 199- 213.

Teece, D.J., Pisano, G. ve Shuen, A. (1997). Dynamics Capabilities and Strategic Management. Strategic Management Journal, 18(7): 509-533.

Truitt, R. H. Ve Kelly, S.K. (1989). Battling a crisis in advance. Public Relations Quarterly, 34, 1, 6-8.

Venkatraman, N. and Ramanujam, V. (1986). Measurement of Business Performance in Strategy Research: A Comparison of Approaches. Academy of Management Review, 1(4), pp.801-808.

Verbeeten, F.H.M. and Boons, A.N.A. (2009). Strategic Priorities, Performance Measures and Performance: An Empirical Analysis in Dutch Firms. European Management Journal, 27, pp.113-128.

Weick K.E. and Sutcliffe, K.M. (2001). Managing the Unexpected: Assuring High Performance in an Age of Complexity. University of Michigan Pressing Problem Series, Jossey-Bass, San Francisco (2001).

Wernerfelt, B. (1984). A resource based view of the firm. Strategic Management Journal, 2(5), 171-180. 
Wheelen, Thomas L. and Hunger, J. David (2000). Strategic Management and Business Policy. Seventh Edition, Pearson Education Inc., New Jersey.

Zahra, S.A. and Bogner, W. (2000). Technology Strategy and Software New Venture Performance: The Moderating Effect of the Competitive Environment. Journal of Business Venturing, 11, pp.189-219. 